\section{Effectiveness of higher order thinking skills activities to the reading comprehension level and academic performance of grade 5 pupils at Kaila Elementary School}

\author{
Binoya, Jane $\$ \\ Emilio Aguinaldo College, Philippines (janebinoya.mnl@eac.edu.ph)
}

Received: 30 March 2021

Available Online: 13 July 2021
Revised: 5 May 2021
DOI: $10.5861 /$ ijrse. 2021.659

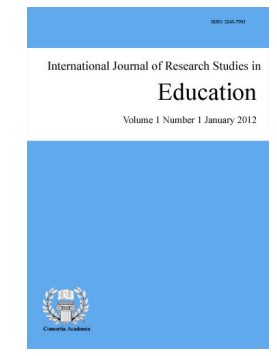

ISSN: 2243-7703 Online ISSN: 2243-7711

OPEN ACCESS

\title{
Abstract
}

Reading comprehension and higher order thinking skills or HOTS usually go with the other. It is important to note that in a study conducted by Singh et al. (2018), it showed teachers struggled to differentiate between lower and higher order thinking skills. It was also reported that teachers find it difficult to introduce higher order thinking skills and were unsure how to employ the best teaching and learning strategies as per the study of Abdul Halim and Siti Muhibah (2015). This study aimed to measure the effectiveness of the Higher Order Thinking Skills activities implemented and analyzed the data gathered from the Phil-IRI test results for the Grade 5 learners of Kaila Elementary School, Division of Antipolo City. The mixed-method research design was used where the researcher has purposively chosen the Control and Experimental Group from the Grade 5 classes. Each group composed of at least 39 members, Grade 5 Mahogany and Tipulo. The age and sex; the reading performance specifically on comprehension based on their Phil-IRI assessment and academic performance of the Grade 5 pupils in the two language subjects- English and Filipino were gathered. Based on the findings, majority of the respondents are in the frustration level during the pretest. On the post test, it is evident that there is an improvement on the level of comprehension for both groups. Traditional strategy can be seen effective however remediation program further helps in improving the performance of students as there are more independent readers in the experimental group based on the post test results. As to the academic performance of the pupils, performance during the second grading period has improved as majority of the respondents in the experimental group gained an outstanding grade from mostly satisfactory grade during the first grading period. The results showed that The HOTS activities given can be regarded as effective measure to improve reading comprehension skills and consequently the academic performance of the pupils. However, teachers have to be trained in order to use these strategies effectively.

Keywords: reading level, reading comprehension, HOTS, academic performance, thinking skills 


\section{Effectiveness of higher order thinking skills activities to the reading comprehension level and academic performance of grade 5 pupils at Kaila Elementary School}

\section{Introduction}

Amid numerous aspects, reading with comprehension gives the learners the confidence to converse with others and express their thoughts through writing. It can be done by improving the ability to understand the language and eventually using and applying it in real-life situations. Among the skills that must be developed for the $21^{\text {st }}$ century, the learner is critical thinking, problem-solving, communication and collaboration, creative and contextual learning, and information and media literacy. These skills can be developed to their best by teaching the learners how to think or commonly using the Higher Order Thinking Skills (HOTS) activities. Moreover, the ultimate goal of a reader is to understand or comprehend what he or she is reading. Therefore, without a solid foundation of reading skills, the researcher feels the children will struggle hard throughout their schooling and adult life. Therefore, the researcher hopes to provide the solid foundation needed to succeed by studying and identifying the best comprehension strategies and teaching these strategies to the pupils. Moreover, this comprehension skill is the most difficult to teach, especially if teachers were not trained enough to teach such skill more so in the two language subjects, which is English and Filipino.

As mentioned in the study conducted by Singh et al. (2018), it showed teachers struggled to differentiate between lower and higher-order thinking skills. It was also reported that teachers found it difficult to introduce higher-order thinking skills and were unsure how to employ the best teaching and learning strategies as per the study of Abdul and Siti (2015). It can be reflected in the current situation in public schools where many pupils were still non-readers or frustrated readers. Even when they already reach the secondary level is an area of concern that must be given focus. Children must have a very good reading foundation to cope up and understand the required competencies and eventually pass the examinations needed. When they know how to understand words and phrases, they will eventually comprehend sentences and articles if given proper assistance.

Kaila Elementary School in the Division of Antipolo City is one among the public schools in the country with learners in the intermediate level who are considered reading challenged pupils. If this problem is not addressed, there would be more complications in their education as they advance to higher levels. Thus, the researcher accepted the challenge and addressed the problem by using Higher Order Thinking Skills activities specifically in the two language subjects (English and Filipino). It was carefully crafted, and the school permission was sought for it to be implemented in the school. The researcher then conducted an experimental study to determine its effectiveness to the selected Grade five (5) learners. First, the said pupils were tested regarding their comprehension level using the standardized test (Philippine Individual Reading Inventory-Phil-IRI), and then the intervention was implemented.

This study is anchored on the most popular theory of Jean Piaget (1950) on Stages of Cognitive Development which focuses on the development of the cognitive aspect of a child. In this study, it was emphasized that a child, when observed closely, has different abilities, specifically on the cognitive aspect. Furthermore, it was also observed that these abilities might also change or develop depending on the processes or interventions given. Thus, the child is treated separately from the knowledge or the perception that he has. He also presented the "sensory-motor stage," "pre-operational stage," "operational stage," and "formal operational stage." These different stages exhibit the stages of development of a child, from acquiring knowledge through the use of senses to learning through plays and then to the stage where they begin to think more deeply and finally to the stage where they can already create abstract ideas.

On the stage that they must begin to think deeply that reading comprehension must be given focus. Reading comprehension must involve an interaction between the reader's world knowledge and the incoming linguistic 
message - many call this the minimal comprehension principle or develop the pupils' Higher Order Thinking Skills. Also, originating from Bloom's taxonomy of learning, HOTs is defined by three upper levels of cognitive skills in the learning hierarchy: analysis, synthesis, and evaluation. Analysis refers to the ability of learners to deconstruct the structure of knowledge and categorize them into their respective groups. For anything that is of the original creation, it would be labeled under synthesis. This cognitive skill can be illustrated using the following verbs: assemble, design, formulate and develop, Narayanan and Adithan (2015).

The study of Nafiseh and Supyan (2014) states that learning HOTs through ICT has a high potential of promoting positive learning outcomes due to the various benefits it brings to the table. However, there are challenges in incorporating ICT in instruction. But, lecturers or teachers can be trained and can explore using simple applications like PowerPoint presentations, adding videos, or simply presenting in the word format. Majumdar (2015) claims that the use of ICT is transforming the nature and process of the learning environment into a new culture. ICT changes the traditional educational approach (teacher-centered learning) into a more interactive and engaging environment to facilitate authentic knowledge transmission. Students become producers of knowledge under the guidance of the teachers (student-centered learning). When students are allowed to use ICT, learning can be more interactive, promoting a higher percentage of learning outcomes.

In schools, techniques can be contextualized. The study of Long and Crookes (2016) revealed a considerable effect on the individual performance of a child if a good and systematic plan was made and implemented. In the Philippine setting, specifically in public schools, applying these learning practices may promote internalizing, processing, or recalling new children's new knowledge. The preparedness of children to use tactics while reading separates effective readers from mediocre ones. For effective readers, this skill will eventually lead them to become effective writers.

In the institution where I belong, a tailor-made solution must be planned, specifically addressing different reading circumstances of the learners. Teachers must think of a more effective strategy for them to be effective facilitators. They will become the reading models for their learners, which will help the learners attain success in the reading aspect. Furthermore, Gringer (2017) emphasized that using varied techniques is more beneficial than conventional ones because it develops children's comprehension. Moreover, the adoption of innovative modes such as active learning or problem-based learning should be encouraged where appropriate to promote the development of communication, problem-solving and self-directed learning skills. The competency of the teachers in teaching thinking skills in the classroom is also one of the crucial factors that help to foster the development of thinking skills among the students, Othman and Mohammad (2014).

On the other hand, Richards and Renandya (2016) depicted cognitive approaches as one that is based on identifying and remembering components of a language. One of which is the utilization of memory to develop an understanding of the difficult terms. "Checking theories such as looking for answers in contextual objects and one's context knowledge and hypothesizing the significance of ambiguous terms and deciding whether it makes sense and, if not, continue at least part of the method may be employed," says Oxford (2016). To encourage learning intellectual rehabilitation in reading, the mentioned strategy can be used and different cognitive functions. The research of Richards (2016) encouraged learners to use a variety of techniques which are enumerated in the succeeding paragraphs. From birth, it is important to teach the importance of reading amongst children and make it a habit, according to Andrew (2016). That is why reading in today's culture is relevant. Reading is best established from childhood.

Given that we can read an article, but we do not get what some can correlate to ecological issues. Reading and listening simply go together. In our classes, we must not require students to have a specific way of writing to dig deeper and discover their abilities. Doing research works helps students in their learning, but if they cannot understand what they have searched for, it doesn't make any sense of doing it, especially if they can't apply it in the real world, and this was emphasized by Skehan (2015). In the study of Moi (2015), he emphasized that reading is the basis or prerequisite of all the subjects, with great consideration in the comprehension aspect. When he gets 
older or when he enters college, he is required to have some book reviews or study different articles where his ability to comprehend will be tested and needed to advance. To become literate, Blickenstaff (2015) states that a child must be taught different ways to understand an article. Assistance then is needed to maintain that momentum that they have when it comes to reading. Educators must then support children in increasing the ability on how they comprehend articles that they read.

Surprisingly, Guimba (2016) urged other researchers to look at different triggers in learning. It also affects the child's literacy. In Particular, he noted in his studies that distress is present amongst the students. He then encourages teachers to address this reading problem by giving interventions, and new teaching approaches appropriate for the child. Hence, developing the pupils' reading comprehension through HOTS can be one of the strategies that teachers must explore to develop a higher level of comprehension of the pupils. It must be noted that this strategy cannot mainly be delivered through verbal sessions but can also be developed by giving them written and/or reflection activities. The online or media platform can be utilized as it is very attractive to children. It must be incorporated in all subjects and lessons so that there is a continuity of exposure and development.

\subsection{Statement of the problem}

This study aimed to determine the effectiveness of higher-order thinking skills activities to the reading comprehension level and academic performance of intermediate learners in the two language subjects at Kaila Elementary School for the School Year 2019-2020. In addition, the results of the study can be used to craft and improve existing intervention activities. Specifically, this study wanted to seek answers on the following:

$>\quad$ What is the intermediate learners' oral and silent reading performance based on their Phil-IRI Assessment in reading comprehension?

$>\quad$ What is the average academic performance of the learners in each of the two language subjects during their 1 st and 2 nd quarters?

$>\quad$ Is there a significant relationship between the learners' performance in reading comprehension with their academic performance in the two language subjects when the HOTS activities were implemented?

\section{Methodology}

This research made use of the mixed method of research. First, the historical and experimental research design was employed. The historical research design analyzed the documents containing the Phil- IRI results of the Grade 5 learners under the control and experimental group. The purpose of choosing this design is to allow the researcher to collect, verify, and synthesize findings from researches already conducted.

Secondly, experimental research design. When we say experimental research, a set of variables is kept constant on the other. The other set of variables are being measured as they are the subject of an experiment. In this study, two groups were subjected to the experiment, the control and experimental group. However, only the experimental group was subjected to the implementation of the Higher-Order Thinking skills activities. The control group was taught reading using the conventional approach.

The subjects of this study comprised the Grade 5 learners of sections Mahogany and Tipulo who composed the control and experimental class or group. These learners were chosen regardless of their demographic profile. These learners are presently studying in Kaila Elementary School for the School Year 2019- 2020 as Grade 5 learners.

\subsection{Research instrument}

The Phil- IRI test results formed part of the documents that were analyzed for this study. In addition, the

38 Consortia Academia Publishing (A partner of Network of Professional Researchers and Educators) 
researcher has also developed Higher Order Thinking Skills activities incorporating ICT. It hoped to improve the learners using a carefully- planned course of action that contains strategies, projects, and activities implemented in the Experimental Group (Grade 5 section Tipulo). This program or intervention activity was submitted to the principal and five (5) other experts in the school for validation. After which, the same was administered to the experimental group.

\subsection{Statistical treatment of data}

To determine the reading comprehension level, the academic performance of the study subjects, the Frequency Distribution, and Percentage were utilized to know the profiles of age and sex of the subject-learners. The subjects in the Phil- IRI tests employed these tools. The researcher also used t-Test to determine the significant difference between the pre-test and post-test scores of the learner-subjects in the experimental class. The Analysis of Variance (ANOVA) was utilized to identify the significant difference between post-test scores of the experimental group when their profiles are taken as test factors.

\section{Results and discussion}

The following are the results and analysis of the data gathered from the Phil-IRI and the pre and post-test scores of the study subjects. Varied statistical treatment methods were utilized to present the results.

Table 1

Frequency and percentage distribution of the pre-test incomprehension

\begin{tabular}{|c|c|c|c|c|c|}
\hline \multirow{2}{*}{\multicolumn{2}{|c|}{$\begin{array}{l}\text { Pre-test } \\
\text { Legend }\end{array}$}} & \multicolumn{2}{|c|}{ Control Group } & \multicolumn{2}{|c|}{ Experimental Group } \\
\hline & & Frequency & Percent & Frequency & Percent \\
\hline Independent & & 11 & 28.21 & 5 & 12.82 \\
\hline Instructional & & 16 & 41.02 & 20 & 51.28 \\
\hline Frustration & & 12 & 30.77 & 14 & 35.90 \\
\hline & Total & 39 & 100.0 & 39 & 100.0 \\
\hline
\end{tabular}

Table 1 proves the frequency and percentage distribution of the pre-test in comprehension. Most respondents from both control group and experimental group has instructional ( $\mathrm{f}=16,41.02$ percent; $\mathrm{f}=20 ; 51.28$ percent); while the some are frustration ( $\mathrm{f}=12$, 30.77; percent; $\mathrm{f}=14 ; 35.90$ percent); and a few are independent $(\mathrm{f}=11,28.21$ percent; $\mathrm{f}=5,12.82$ percent). Therefore, the majority of respondents are instructional when gauge based on comprehension.

\section{Table 2}

Frequency and percentage distribution of the post-test incomprehension

\begin{tabular}{|c|c|c|c|c|}
\hline \multirow{2}{*}{$\begin{array}{l}\text { POST-test } \\
\text { Legend }\end{array}$} & \multicolumn{2}{|c|}{ Control Group } & \multicolumn{2}{|c|}{ Experimental Group } \\
\hline & Frequency & Percent & Frequency & Percent \\
\hline Independent & 14 & 35.90 & 20 & 51.28 \\
\hline Instructional & 16 & 41.03 & 19 & 48.72 \\
\hline Frustration & 9 & 23.08 & 0 & 0.0 \\
\hline Total & 39 & 100.0 & 39 & 100.0 \\
\hline
\end{tabular}

Table 2 reveals the frequency and percentage distribution of the post-test incomprehension. In the control group, majority are instructional $(\mathrm{f}=16,41.03$ percent); followed by independent $(\mathrm{f}=14,35.90$ percent); and frustration readers $(\mathrm{f}=9,23.07$ percent). Yet, for the experimental group, most $(\mathrm{f}=20,51.28$ percent) are independent; several ( $\mathrm{f}=19,48.72$ percent) are instructional. It can be seen that there is an improvement in the level of comprehension for both groups during the post-test. Traditional strategy can be seen as effective. However, HOTS activities are given through the use of ICT, or another online platform further helps in improving the performance of the pupils. 
Binoya, J.

Table 3

The average grade of pupils in English and Filipino during the first grading period

\begin{tabular}{|c|c|c|c|c|c|}
\hline \multirow{2}{*}{ Grading Scale } & \multicolumn{2}{|c|}{ Control Group } & \multicolumn{2}{|c|}{ Experimental Group } & \multirow{2}{*}{ Achievement Level } \\
\hline & Pupils & Percent & Pupils & Percent & \\
\hline $90-100$ & 0 & 0.00 & 0 & 0.00 & Outstanding \\
\hline $85-89$ & 7 & 17.95 & 10 & 25.64 & Very Satisfactory \\
\hline $80-84$ & 17 & 43.59 & 24 & 61.54 & Satisfactory \\
\hline $75-79$ & 15 & 38.46 & 5 & 12.82 & Fairly Satisfactory \\
\hline Below 75 & 0 & 0.00 & 0 & 0.00 & Did Not Meet Expectation \\
\hline Total & 39 & 100.0 & 39 & 100.0 & \\
\hline Mean & \multicolumn{2}{|c|}{80.97} & \multicolumn{2}{|c|}{82.64} & \\
\hline Standard Deviation & \multicolumn{2}{|c|}{3.6597} & \multicolumn{2}{|c|}{3.0735} & \\
\hline
\end{tabular}

Table 3 reveals the average grade of pupils in English and Filipino during the first grading period. Most ( $\mathrm{f}=$ $17,43.59$ percent) of the respondents from the control group obtained a grade of 80 to 84 or satisfactory; some $(\mathrm{f}=15,38.46$ percent) have 75 to 79 or fairly satisfactory; and few ( $\mathrm{f}=7,17.85$ percent) got 85 to 89 or very satisfactory. For the experimental group, the majority ( $\mathrm{f}=24,61.54$ percent) achieved 80 to 84 or satisfactory; followed by 85 to 89 or very satisfactory ( $\mathrm{f}=10,25.64$ percent); and 75 to 79 or fairly satisfactory $(\mathrm{f}=5,12.82$ percent). Data indicates that respondents have average performance in first grading.

\section{Table 4}

The average grade of pupils in English and Filipino during the second grading period

\begin{tabular}{|c|c|c|c|c|c|}
\hline \multirow{2}{*}{ Grading Scale } & \multicolumn{2}{|c|}{ Control Group } & \multicolumn{2}{|c|}{ Experimental Group } & \multirow{2}{*}{ Achievement Level } \\
\hline & Pupils & Percent & Pupils & Percent & \\
\hline $90-100$ & 0 & 0.00 & 23 & 58.97 & Outstanding \\
\hline $85-89$ & 9 & 23.08 & 16 & 41.03 & Very Satisfactory \\
\hline $80-84$ & 19 & 48.72 & 0 & 0.0 & Satisfactory \\
\hline $75-79$ & 11 & 28.21 & 0 & 0.0 & Fairly Satisfactory \\
\hline Below 75 & 0 & 0.00 & 0 & 0.0 & Did Not Meet Expectation \\
\hline Total & 39 & 100.0 & 39 & 100.0 & \\
\hline Mean & \multicolumn{2}{|c|}{81.74} & \multicolumn{2}{|c|}{91.72} & \\
\hline Standard Deviation & \multicolumn{2}{|c|}{3.6280} & \multicolumn{2}{|c|}{3.9864} & \\
\hline
\end{tabular}

Table 4 displays the academic performance of the pupils during second grading. The majority $(\mathrm{f}=19,23$. 08 percent) of the respondents from the control group gained a grade of 80 to 84 or satisfactory; some ( $\mathrm{f}=11,28$. 21 percent) have 75 to 79 or fairly satisfactory; and few ( $f=9,23.08$ percent) got 85 to 89 or very satisfactory. In the experimental group, most ( $\mathrm{f}=23,58.97$ percent) achieved 90 to 100 or outstanding; followed by 85 to 89 or very satisfactory $(\mathrm{f}=16,41.03$ percent. Data indicates that most of the experimental group respondents have higher grades during the second grading period than in the control group.

Table 5

Relationship between the reading comprehension of pupils with their academic performance in the first grading

\begin{tabular}{lccccccc}
\hline & $\mathrm{N}$ & Mean & $\mathrm{SD}$ & $\begin{array}{c}\text { Computed } \\
\text { t-Value }\end{array}$ & P-Value & Decision & Interpretation \\
\hline Control Group & 39 & 80.97 & 3.6597 & -1.36489 & .12201 & Accept Ho & NS \\
Experimental Group & 39 & 82.64 & 3.0735 & & \\
\hline
\end{tabular}

Table 5 shows the significant relationship between the reading comprehension level of the pupils with their academic performance in the first grading was, control group $(\mathrm{N}=39, \overline{\mathrm{x}}=80.97, \mathrm{SD}=3.6597)$ and experimental $(\mathrm{N}=39, \overline{\mathrm{x}}=82.64, \mathrm{SD}=3.0735)$ obtained at- value of -1.36489 and $\mathrm{p}$-value of .12201 . Therefore, the first grading grade in the two language subjects has no significant relationship with the reading comprehension level of the pupils. Other contributing factors affect students' performance aside from reading comprehension skills.

The factors include the ability to recognize and recall the components of the language to develop their 
HOTS activities to the reading comprehension level and academic performance of grade 5 pupils

ability in learning and understanding new terms, according to Richards and Renandya (2016), and these things are all part of the cognitive process. For this to be solved, giving reading exercises frequently will be of great help to help them have that focus and sustain their interest in reading.

Table 6

Relationship between reading comprehension of the pupils in their academic performance in second grading

\begin{tabular}{lccccccc}
\hline & $\mathrm{N}$ & Mean & SD & $\begin{array}{c}\text { Computed } \\
\text { t-Value }\end{array}$ & P-Value & Decision & Interpretation \\
\hline Control Group & 39 & 81.74 & 3.6280 & 0.00017 & .039938 & Reject Ho & $\mathrm{S}$ \\
Experimental Group & 39 & 83.41 & 2.5517 & Ro & \\
\hline
\end{tabular}

Table 6 illustrates the substantial relationship between the reading comprehension level of the pupils with their academic performance in second grading were, control group $(\mathrm{N}=39, \overline{\mathrm{x}}=81.74, \mathrm{SD}=3.6280)$ and experimental $(\mathrm{N}=39, \overline{\mathrm{x}}=83.41, \mathrm{SD}=2.5517)$ achieved $\mathrm{t}$ - the value of 0.00017 and $\mathrm{p}$-value of .039938 . As a result, second grading has a significant relationship with their reading comprehension skills. This may be because of the implemented Higher Order Thinking Skills activities where the learners' scores in the experimental group improved.

As Andrew (2016) mentioned, reading is essential at the very start of childhood, and it must be continued to develop a reading habit for the children. It may not be important for them, but they will eventually realize the importance of it when they grow up. Therefore, a routine in reading must be founded at the earliest possible time, which is childhood. Also, involving in interesting and relevant Higher order thinking skills is a very important component that can prepare students to solve problems in the 21 st century, as claimed by Retnawati (2018).

\section{Conclusions and Recommendations}

With the world's current situation, the use of information and communication technology (ICT) in almost any individual's life is very important. On this note, teachers have to learn and adapt themselves to a digital world where there are many sources and online tools. Furthermore, the rapid advances in technological tools and their related complexity allow innovative yet interactive forms of learning, teaching, interaction, and communication.

From this research, it can be seen that learning HOTs through ICT has a high potential of promoting positive learning outcomes due to the various benefits it brings to the table. The challenges in using and integrating technology in the learning environment are not a dead end as such obstacles can be developed in teachers as long as they keep themselves up to date with current ICT trends, Nafiseh Zarei and Supyan Hussin (2014), such as using PowerPoint presentations and utilizing E-learning in their tertiary classrooms.

Specifically, based on the study results, the following conclusions can be drawn: First, the majority of respondents are at the instructional level when gauge based on reading comprehension during the pre-test.

Second, during the post-test, most of the pupils in the control group are still at the instructional level. In contrast, in the experimental group, most of them advanced to the independent level of reading comprehension. Therefore, improvement of comprehension level is more evident in the experimental group compared to the control group. Thus, the traditional strategy can be seen as effective however remediation programs, particularly the incorporation of HOTS activities through the use of ICT, further helps in improving the performance of the pupils.

Third, the academic performance of the study subjects in the control and experimental group indicates that they have average performance in first grading based on the data presented.

Fourth, during the second grading, data indicates that most of the experimental group respondents have higher grades during the second grading period than in the control group. 
Fifth, the study also shows that the first grading grade of the pupils in the two language subjects of both groups has no significant relationship with their reading comprehension level. Other contributing factors affect students' performance aside from reading comprehension skills.

Lastly, the post-test results illustrate the substantial relationship between the reading comprehension level of the pupils with their academic performance in second grading. The improved academic performance of the respondents was influenced by their reading comprehension skills brought about by the implemented HOTS activities with ICT in the experimental group.

The following suggestions are recommended to the following:

$>\quad$ Schools Division Office/ Curriculum Planners should revisit policies that will improve instruction methods that cater to the Higher Order Thinking Skills of pupils to increase their reading comprehension and eventually improve their academic performance.

$>$ Administrators should initiate programs and activities that will engage pupils to endure challenges in their abilities in reading, especially in comprehending what they are reading.

$>$ Teachers should stress the importance of comprehension. They must also submit to training or studies in integrating ICT and HOTS activities to develop their pupils' comprehension. Also, they may be able to give facts to pupils in ways that will best cater to their learning needs.

$>\quad$ Students should invest themselves in activities that develop their understanding of everything that they see and read. Comprehension is an essential need that leads to a better life.

$>$ Future Researchers can explore other HOTS activities and integration and their effect on the teaching-learning process. Further, this may also serve as a reference for them to conduct studies of the same nature.

\section{References}

Andrew, P. (2016). Reading is important. Retrieved April 3, 2019 from https://www.knowswhy.com/why-is-reading-important/

Azian, F. I. (2017). Investigating the implementations of higher order thinking skills in Malaysian classrooms: Insights from L2 teaching practices. Sains Humanika, 65-73.

Blickenstaff, J., Hallquist, E., \& Kopel, K. (2015). The effects of reading strategies in comprehension for elementary age learners an action research report. St. Catherine University St. Paul, Minnesota. Retrieved April 3, 2019 from https://sophia.stkate.edu/cgi/viewcontent.cgi?article=1001\&context=maed

Guimba, W.D. \& Alico, J.C. (2016) Reading anxiety and comprehension of grade 8 Filipino learners in Mindanao State University. International Journal of Humanities and Social Sciences. Retrieved April 3, 2019 from http://www.ijhss.net/index.php/ijhss/article/viewFile/42/18

Long, C. A., \& Cookes, D. E. (2016). The effectiveness of a group reading instruction program with poor readers in multiple grades learning. Disability Quarterly, 24(2), 119-135. https://doi.org/10.2307/1511068

Moi, L. (2015). Reading is important. Retrieved from https://www.worksheetcloud.com/blog/why-is-reading-important

Nafiseh, Z., \& Supyan, H. (2014). Impact of learning management blog on students' language learning and acquisition. GEMA Online Journal of Language Studies, 14(3), 51-63. https://doi.org/10.17576/GEMA-2014-1403-04

Narayanan, R., (2015). The teaching of higher order thinking skills in Malaysia. Journal of Southeast Asian Education, 1-21.

Othman, J., \& Mohamad, L. (2014) Thinking skill education and transformational progress in Malaysia. International Education Studies, 7(4), 1-4. https://doi.org/10.5539/ies.v7n4p27 
HOTS activities to the reading comprehension level and academic performance of grade 5 pupils

Retnawati, H., Djidu, A. Kartianom, E., \& Risqa, D. A. (2018). Teachers' knowledge about higher-order thinking skills and its learning strategy. Problems of education in the 21 st century, 76(2). https://doi.org/10.33225/pec/18.76.215

Richards, J. M., \& Renandya, K. (2016). Meta-analysis of reading comprehension interventions for students with learning disabilities: Strategies and implications. Reading Improvement, 44(10), 6- 22.

Singh, C. K., Mohtar, T., \& Mostafa, N. et al. (2018). A review of research on the use of higher order thinking skills to teach writing. International Journal of English Linguistics, 8. 23-61. https://doi.org/10.5539/ijel.v8n1p86

Thomas, W. T. (2018). An analysis of learner-problems in the development of English language reading comprehension among secondary school students in Vihiga District Kenya. Kenyatta University. 
Binoya, J.

44 Consortia Academia Publishing (A partner of Network of Professional Researchers and Educators) 